\title{
Use of LHP for cooling power electronic components
}

\author{
M. Smitka ${ }^{1, a}$, M. Malcho ${ }^{1}$, P. Nemec ${ }^{1}$, and Z. Kolková ${ }^{1}$ \\ ${ }^{1}$ University of Žilina, Departure of Power Engineering, Univerzitna 1, 01026 Žilina, Slovakia
}

\begin{abstract}
The paper deals with use of cooling equipment build on basis two phase thermosyphon loop. This device belongs to a group of loop heat pipe (LHP). This LHP is a two-phase device with extremely high effective thermal conductivity that utilizes the thermodynamic pressure difference to circulate fluid. It was invented in Russia in the early 1980's. Thermosyphon loop is similar as LHP but it doesn't contain wick and circulation of the fluid using gravitation force instead of capillary pressure as it is in LHP. The work deals with the cooling insulated gate bipolar transistor with $370 \mathrm{~W}$. The paper describes the course of the heat dissipation using ribbed cooler for natural convection and using fin for forced convection. The results are compared with heat dissipation through thermosyphon loop.
\end{abstract}

\section{Introduction}

Given the rapid progress in the electronics industry, the thermal management of electronic components becomes an important and serious issue. Miniaturization of devices and increase their performance leads to increased heat flow. Natural and forced cooling for heat sink are often deficient and thus is limited to low and medium heat flux.

One possibility for heat dissipation for high heat flux is using thermosyphon loop. A simplified schematic of a loop thermosyphon is shown in Figure 1, to better describe the modeling domain. The driving force for the passive loop thermosyphon design is in the head of liquid under the condenser. The head of liquid acts to displace the less dense vapor in the evaporator, creating a twophase flow towards the condenser. It is noted that the current loop thermosyphon is approximately 1 meter in height. The total height is much higher than traditional heat pipes/thermosyphons. In cases with less gravitational head, fluid exits the pool as single-phase saturated vapor after phase change in the evaporator (and may be driven by the capillary forces of a wick). The added gravitational head in this study is sufficient to drive excess liquid flow to the evaporator generating two-phase flow towards the condenser [1].

The thermosyphon may be designed as a thermosyphon pipe consisting of a straight tube in vertical or an inclined position, which is filled with a certain amount of refrigerant. Heat is transferred as heat of vaporization from the evaporator to the condenser inducing counter current two-phase flow in between the two. A thermosyphon loop consists of an evaporator and a condenser connected by two tubes, a riser and a downcomer. With the aim of obtaining a small temperature difference across the thermosyphon, the evaporator and condenser parts of the loop may be designed with channel geometries enhancing heat transfer in boiling and condensation. Such a device is here called an advanced thermosyphon loop.

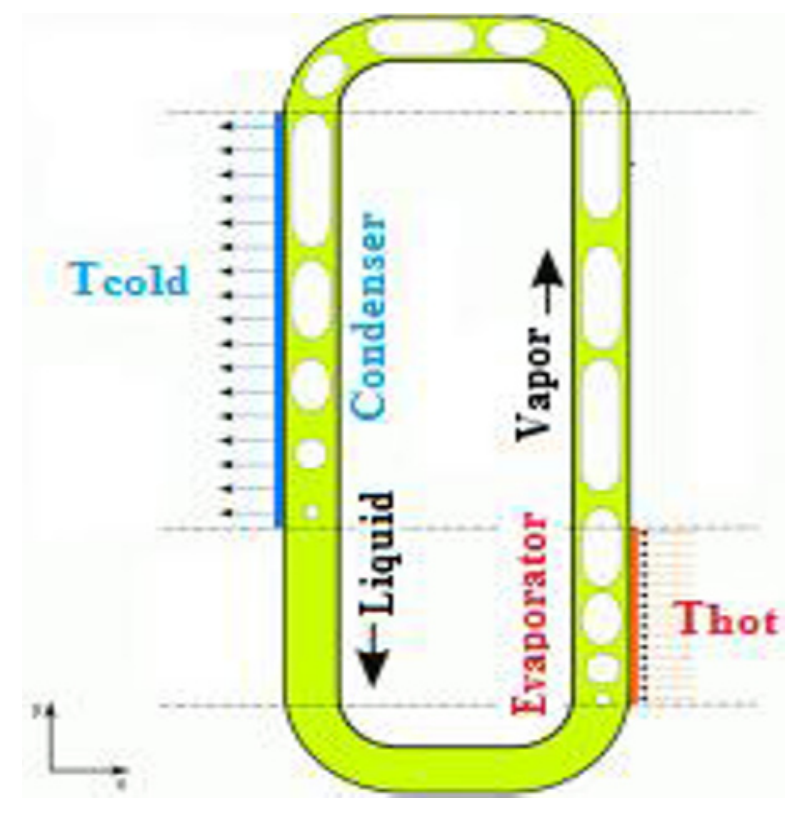

Fig. 1. Principle of operation of thermosyphon loop.

The advantages compared to the thermosyphon pipe, are the possibility of using narrower channels in connecting tubes, higher heat transfer coefficients and flexible design of the evaporator for close contact between the component and refrigerant channels. In either case, thermosyphon loop don't need mechanical

\footnotetext{
a martin.smitka@fstroj.uniza.sk
} 
devices for circulation of flud. The heat transfer performance of the system depends on the design of the thermosyphon system and the choice of working fluid in the system (Palm and Khodabandeh [2]). The temperature difference between the evaporator wall and the refrigerant in the evaporator is the most critical criteria for the thermal performance of the thermosyphon system.

\section{Design of experimental device}

The cooling system is designed as thermosyphon loop with fluorinert FC72 as working fluid. Device is shoved in figure 2.

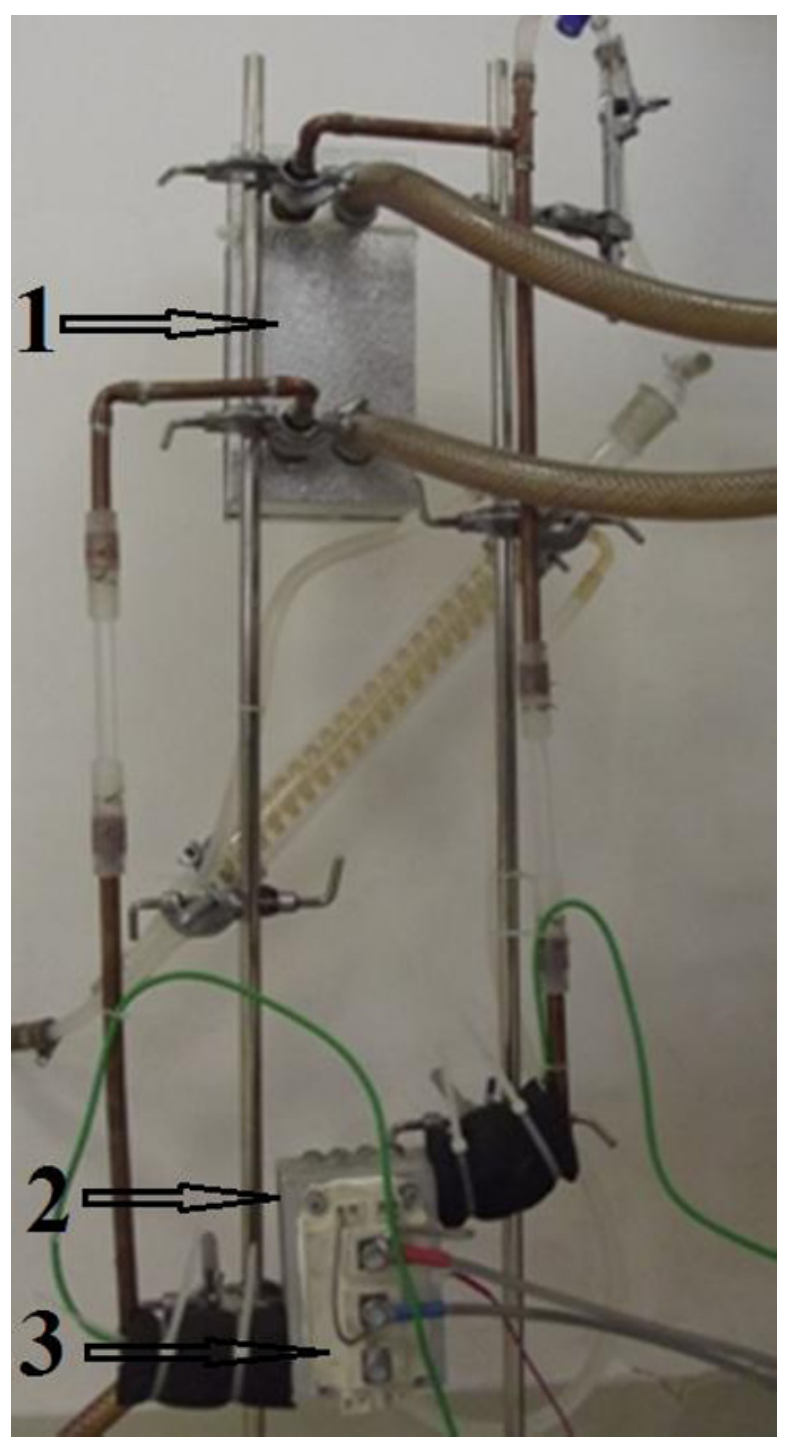

Fig. 2. Scheme of thermosyphon loop: 1- condenser, 2evaporator, 3- electronic component

The evaporator consists of aluminum block with dimension $110 \times 63 \times 30 \mathrm{~mm}$. Into this block is drilled 9 vertical holes with a diameter $\Phi=6 \mathrm{~mm}$. At the bottom and top are this hole connected to each other by drilling horizontal hole with a diameter $\Phi=12 \mathrm{~mm}$. Section of evaporator is shown in figure 3 . On the evaporator is fixed electrical component (Insulated gate bipolar transistor). Heat loss from electrical component is inducted to aluminum block, which heads working fluid. Then it is vaporized and vapor goes to the condenser.
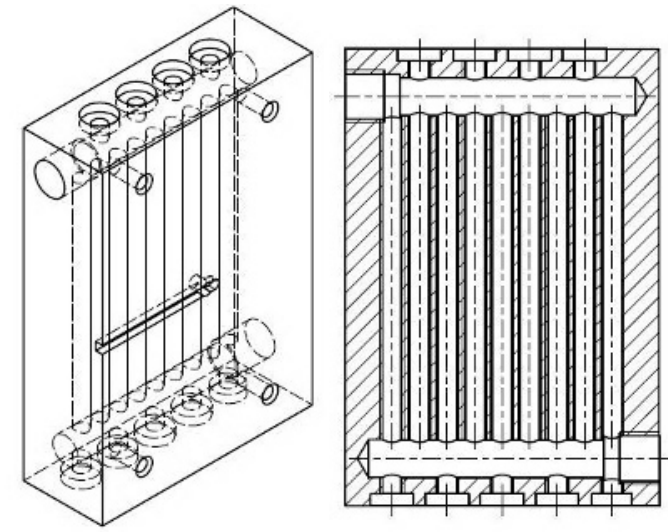

Fig.3. Section of evaporator.

The condenser is consisted of plate heat exchanger Alfa Laval B5, which 10 metal plates, molded highquality stainless steel. The maximum volume of the channel is $24 \mathrm{ml}$ and the maximum flow rate is $4 \mathrm{~m} / \mathrm{s}$. Plates are folded together for pass primary and secondary fluid. The heat is transferred thought the plates so there is heat transfer between fluids. Working fluid for thermosyphon loop is Fluorinert FC72 and cooling fluid is water. The section of condenser is in figure 4.
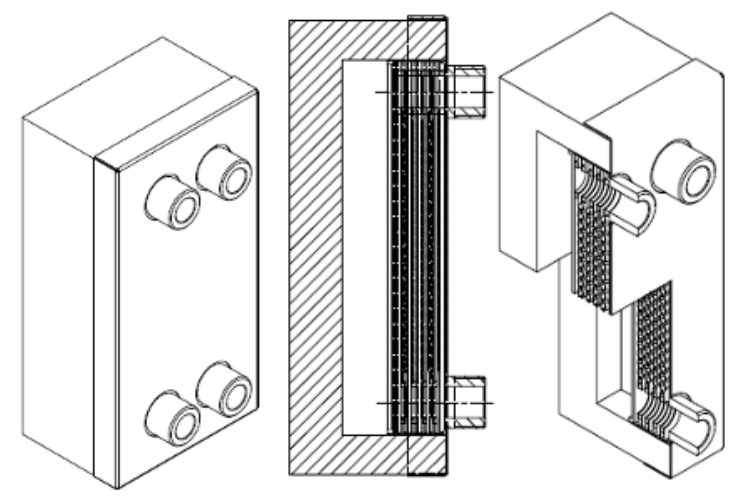

Fig. 4. Section of condenser.

\section{Results and discussion}

For determining of the performance parameters of thermosyphon loop were made number of measurements, which were compared with cooling system with fin cooler with and without forced convection. For achieving the forced convection was used fan. The maximum permissible temperature of electrical component was 100 ${ }^{\circ} \mathrm{C}$.

\subsection{Cooling with fin cooler without forced convection}

Cooler was made of aluminum fins and it was attached to an electronic component. Between the contact area was fixed thermocouple and temperature was measured. Series of measurements was found temperature 
dependence on the time when power of source was changed. The speed of air $\left(w_{\text {air }}\right)$ was zero. Figure 5 gives temperature dependence of the performance.

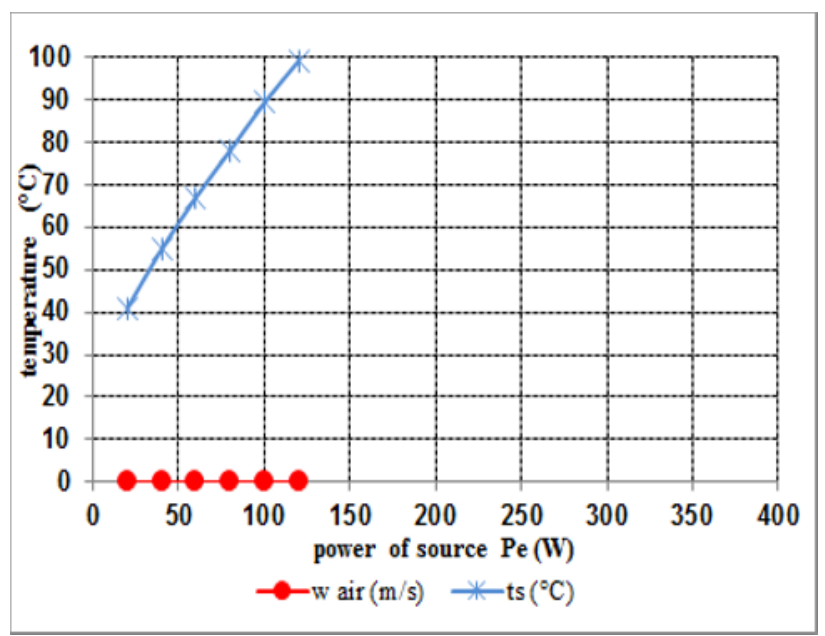

Fig. 5. Temperature dependence of the contact area to power dissipation at ribbed natural convection cooling in air.

\subsection{Cooling with fin cooler with forced convection}

To increase the heat transfer from electronic component has been used forced convection induced by fan. The aluminum cooler was the same as for natural convection cooling. Cooler was blown with fan at the constant speed $\left(w_{\text {air }}\right)$ of $5 \mathrm{~m} / \mathrm{s}$, which was fixed on the electronic component. Results of measurements can be seen in figure 6 .

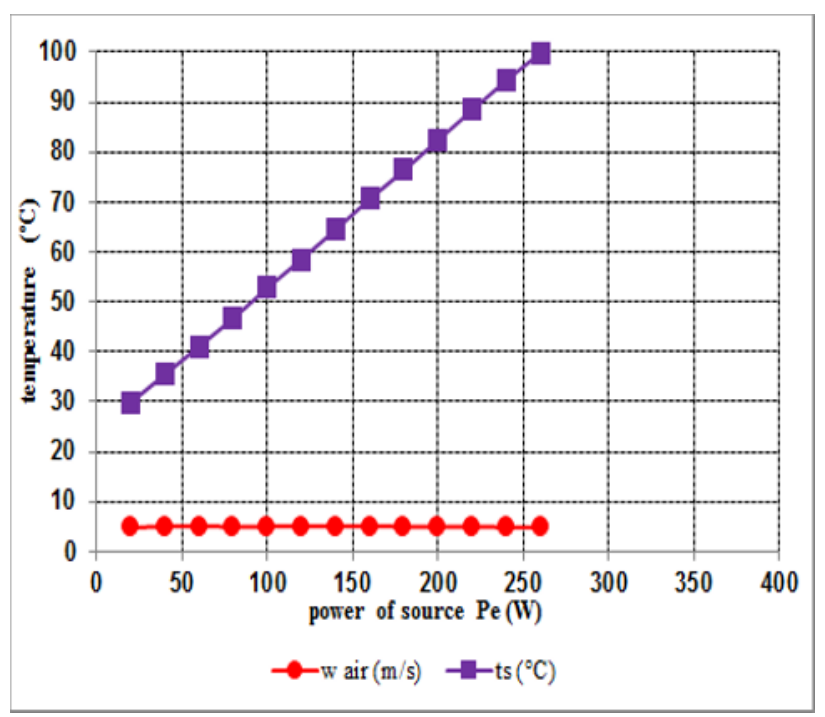

Fig. 6. Temperature dependence of the contact area to power dissipation at ribbed forced convection cooling in air.

\subsection{Cooling with thermosyphon loop}

Measurements were performed at increasing performance of electronic component from $20 \mathrm{~W}$ to $370 \mathrm{~W}$. Electronic component was connected to DC power source HEWLET
PACKARD 6575A, (DC POWER SUPLY 0-120V/0$18.5 \mathrm{~A})$, which was used for heated evaporator of thermosyphon loop. The maximum permissible temperature of electronic component is $100{ }^{\circ} \mathrm{C}$. Supplying heat for heat pipe, the working fluid is heated to the boiling point and begins to evaporate. Vapor of working fluid passes through evaporator line to condenser. In the condenser vapor condenses and liquid phase drips back into the evaporator of thermosyphon loop.

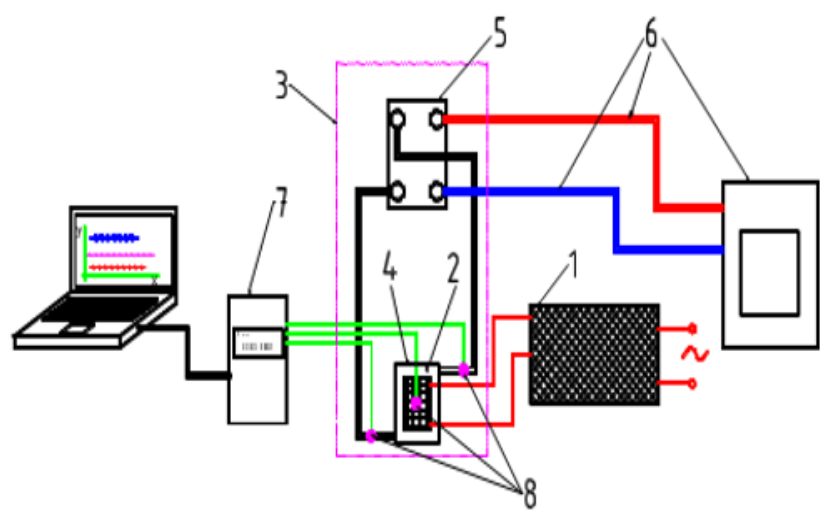

Fig. 7. Schematic diagram of measuring device: 1 - power supply voltage and current, 2 - electronic element 3 thermosyphon loop, 4 - evaporator, 5 - condenser, 6 - cooling circuit with thermostat, 7 - logger, 8 - thermocouples.

The involvement of measuring device can be seen in figure 7. As a refrigerant fluid was used water and temperature of water was controlled by the thermostat. Measurement was made for different types of temperature water $\left(t=20^{\circ} \mathrm{C}, 30^{\circ} \mathrm{C}, 40^{\circ} \mathrm{C}, 50^{\circ} \mathrm{C}\right)$.

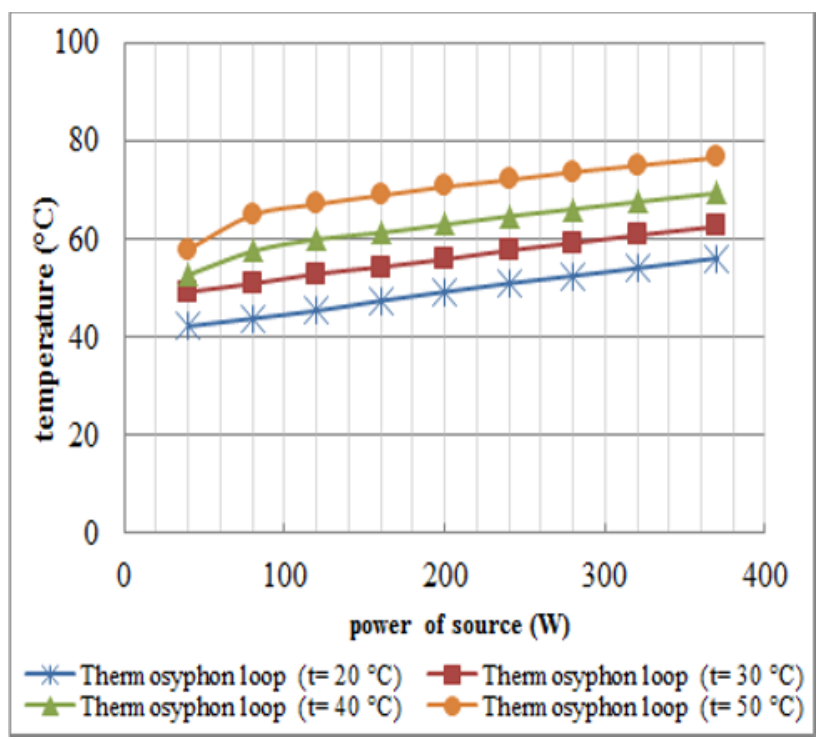

Fig. 8. Temperature dependence of the contact area to power dissipation for different type of water temperature.

In figure 8 can be seen as increasing of power of source increasing temperature of electronic component but temperature doesn't exceed the value $100{ }^{\circ} \mathrm{C}$ even at full power $(370 \mathrm{~W})$. Using $50{ }^{\circ} \mathrm{C}$ refrigerant fluid the 
temperature of electronic component doesn't exceed more than $80{ }^{\circ} \mathrm{C}$ at full power of source. Using $20{ }^{\circ} \mathrm{C}$ refrigerant fluid the electronic component doesn't exceed $60{ }^{\circ} \mathrm{C}$. It gives good assumption for cooling of power components.

In figure 9 it can be observed different between cooling systems. There is cooling system with using fin cooler with natural convection, fin cooler with forced convection and thermosyphon loop. It can be observed, that fin cooler with natural convection is not sufficient to exhaust heat loss at full power of source. The same is true for fin cooler with forced convection. In this case is preferable to use Thermosyphon loop. Thermosyphon loop can be used for full power of electronic component $(370 \mathrm{~W})$.

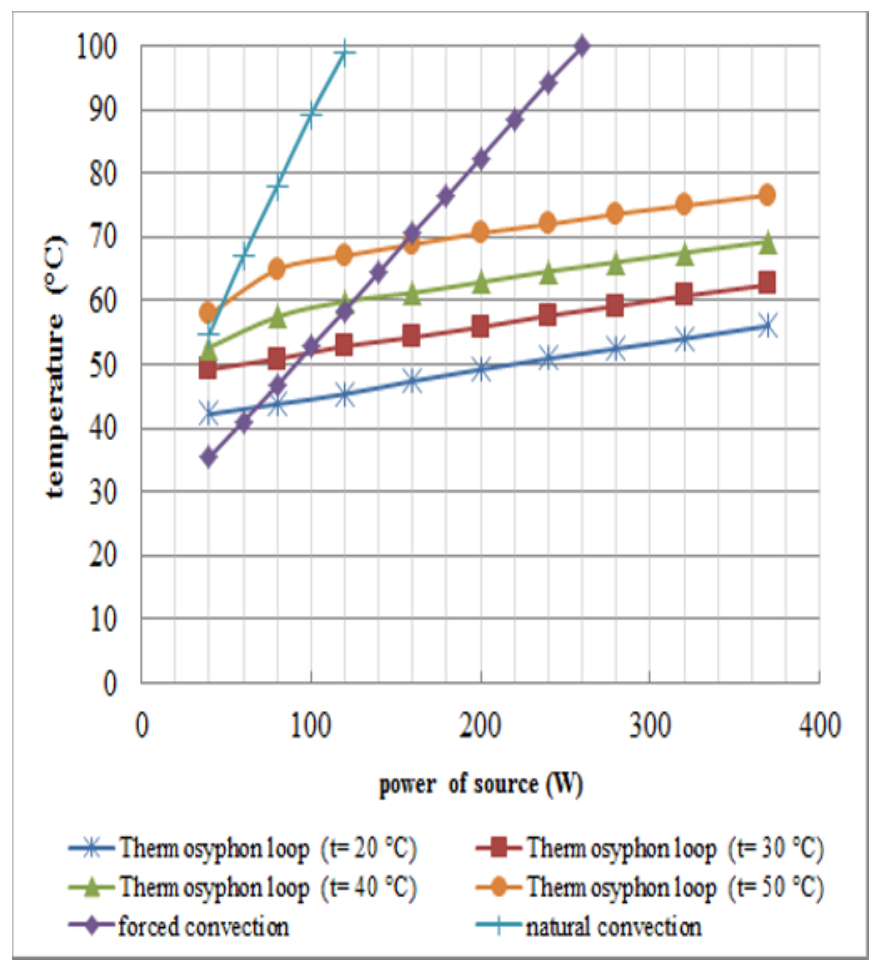

Fig. 9. Comparison course of temperatures for different power dissipation cooling system.

\section{Conclusions}

Aim of the experiment was to design the prototype LHP based on thermosyphon loop, confirm function loop and compare its performance with air cooler for natural and forced convection. Through experimental measurements thermosyphon loop, it has been demonstrated good cooling effect. Event at full power electronic component and also at the highest temperature of cooling fluid $50{ }^{\circ} \mathrm{C}$ uses for cooling working fluid in loop, the temperature of electronic component doesn't exceed $80{ }^{\circ} \mathrm{C}$. This experiment demonstrates the quality of thermosyphon loop and its merits of using for cooling highperformance electronic devices. The application of thermosyphon loop for cooling power electronic, especially electronic semiconductor devices, offers better cooling performance and improved cooling in area of higher power dissipation of about $0.5 \mathrm{~kW}$.

\section{Acknowledgement}

This paper was created within the solution of project APVV-0577-10 and 064ŽU-4/2012.

\section{References}

1. J. Hartenstine, R. Bonner, J. Mongomery, T. Sementic, In Proceeding of IPACK, Vancouver, CANADA (2007)

2. J. C. Ruppersberg, R.T. Dobson, In Journal of Energy in Southern Africa, No 3, (2007)

3. J. Andrews, A. Akbarzadeh, I. Sauciuc, Heat pipe technology: Theory, applications and prospects (Melbourne: PERGAMON, 1996)

4. D. Reay, P. Kew, Burlington: Elsevier, Heat PipesTheory, Design and applications. (Burlington: Elsevier, 2006)

5. M. Suchovský, Experimental verification of the performance parameters of loop heat pipe (Žilina: University of Žilina, 2012)

6. K. Kaduchová, R. Lenhard, J. Jandačka, The application of experimental and numerical methods in fluid mechanics and energy 2012 : 4 119(2012)

7. K. Kaduchová, R. Lenhard, J. Jandačka, Experimental fluid mechanics 2011(2011)

8. S. Gavlas, J. Jandačka, J. Kadúchová, R. Lenhard, Transport phenomena : the sixth international conference (2011)

9. S. Gavlas, R. Lenhard, 5th Annual International Travelling Conference for Young Researchers and PhD students. 2011

10. M. Jakubský, R. Lenhard, M. Vantuch, Energetika a životní prostředí $2010=$ Power engineering and environment (2010) 